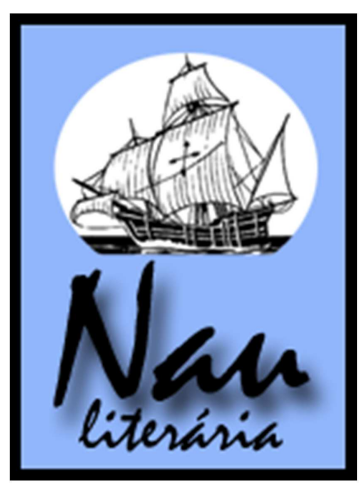

\title{
A morte do mundo e o nascimento do monstro: entre revelações e regressos
}

\author{
Rosana Cristina Zanelatto Santos* \\ Juliana Ciambra Rahe*
}

\begin{abstract}
Resumo: Este artigo esboça uma análise acerca da presença do monstruoso em Antes de nascer o mundo, de Mia Couto. O monstro é uma construção cultural que obriga o indivíduo a abdicar de seu corpo e de sua identidade, privando-o de ocupar determinados espaços. Silvestre Vitalício, o patriarca de Antes de nascer o mundo, contará com o auxílio da visitante/enviada portuguesa, Marta, para exorcizar o monstro que tomou corpo em si, tendo como modus operandi a reinvenção de sua identidade cultural.
\end{abstract}

Palavras-chave: Monstro; Identidade; Tradução cultural; Mia Couto.

\begin{abstract}
This paper aims to analyze the presence of the monstrous in Antes de nascer o mundo by Mia Couto. The monster is build by a society that forces the individual to abdicate its own body and own identity and deprives him/her from occupying some spaces. Silvestre Vitalício, the patriarch of Antes de nascer o mundo, of relies on the help of the visitor/ envoy Portuguese, Marta, to exorcize the monster that was embodied in itself through the reinvention of its cultural identity.
\end{abstract}

Keywords: Monster; Identity; Cultural translation; Mia Couto.

\section{Introdução}

O monstro é, segundo Sérgio Luiz Prado Bellei, "[...] aquela criatura que se encontra na ou além da fronteira, mas está sempre e paradoxalmente próximo e distante do humano, que tem por função delimitar e legitimar" (2000, p. 11). Ele responde a necessidades culturais diferentes conforme o momento histórico em que surge e permite a compreensão dessas necessidades. Os monstros "[...] nos perguntam por que os criamos" (COHEN, 2000, p. 55), enquanto nos perguntamos por que precisamos dos monstros para nos indagar a nós mesmos e à nossa humanidade.

"Os monstros desempenham, reconhecidamente, um papel político como mantenedor de regras sociais" (JEHA, 2007, p. 18). Eles constituem uma manobra para delimitar fronteiras, estabelecendo proibições para alguns comportamentos e valorizando outros.

\footnotetext{
* Doutora em Letras (USP). Bolsista de Produtividade em Pesquisa - CNPq - nível 2. Ingresso na UFMS em 1993, no Câmpus de Dourados, hoje UFGD (Universidade Federal da Grande Dourados), no Curso de Letras. Em 2004, transferência para o Câmpus de Campo Grande da UFMS, para o Depto. de Letras, no qual trabalha até hoje. Atualmente é Coordenadora de Pesquisa da UFMS.

${ }^{* *}$ Graduada em Letras pela UFMS e mestranda em Estudos de Linguagens pela mesma IFES.
} 
Assim, o corpo monstruoso constitui "[...] uma narrativa dupla, duas histórias vivas: uma que descreve como o monstro pode ser e outra - seu testemunho - que detalha a que uso cultural o monstro serve" (COHEN, 2000, p. 42). Como postulado por Jeha,

[...] os monstros ajudam a manter a coesão social. Os grupos precisam manter seus membros unidos dentro de fronteiras e proteger-se contra os inimigos externos. A harmonia interna depende de uma percepção coletiva de realidade, sinalizando àqueles que a compartilham que 'as coisas são assim' e não de outra maneira e 'é assim que devemos fazer as coisas por aqui'. Qualquer transgressão das fronteiras ou limites estabelecidos pelo grupo, quer sejam abstratos ou concretos, causa desconforto e requer que o mundo retorne ao estado considerado certo. $\mathrm{O}$ monstro é um artifício para rotular as infrações desses limites sociais. (JEHA, 2009, p. 19)

A criatura monstruosa corporifica um momento cultural na sociedade e possibilita a realização de uma leitura de uma cultura a partir das relações que a geram. A investigação da monstruosidade de Silvestre Vitalício, o patriarca do romance Antes de nascer o Mundo, do moçambicano Mia Couto, conduz a um possível entendimento da cultura que o gerou, revelando-nos os limites e traçando fronteiras que não devem ser transpostas na busca pela construção de uma possível, entre as possíveis, identidade moçambicana, bem como os caminhos a serem percorridos no exorcismo do monstro. Isso se dá por meio da (re)invenção identitária, o que pode promover a reintegração de Vitalício, a corporificação de Moçambique ao mundo após a espoliação sofrida com o processo de colonização e de descolonização.

Assim, a monstruosidade de Silvestre Vitalício reconhece uma anomalia resultante do colonialismo e de seu esgarçamento, que deixa as identidades fluidas, em estado de problematização. O monstro é amedrontador porque solapa as fronteiras reconhecidas como fundadoras de uma certa (des)ordem, o que, no entanto, pode (re)apresentar na própria doença a sua cura.

\section{2 "Meu pai, Silvestre Vitalício"}

Em Antes de Nascer o Mundo, de Mia Couto, Mwanito conta a história da humanidade que, conforme lhe explicara o pai, era composta por apenas cinco homens. Eles resistiram à morte do mundo: Mwanito, seu irmão Ntunzi, seu pai Silvestre, o serviçal Zacaria Kalash e o Tio Aproximado, além da jumenta Jezibela. O extinguir do mundo, conforme a Mwanito revelou o pai, se deu por definhamento. O cosmos se exauriu em desespero e os últimos sobreviventes passaram a habitar um lugarejo ao qual Silvestre Vitalício batizou Jesusalém. Além do horizonte, existiam apenas territórios sem vida aos quais se chamava "Lado-de-Lá".

O abandono das cidades do mundo e a mudança para Jesusalém ocorreram após o falecimento de Dordalma, esposa de Silvestre. Em Jesusalém, o velho Vitalício buscava emigrar-se de si mesmo. "[...] Quem perde a esperança, foge. Quem perde a confiança, 
esconde-se. E ele queria as duas coisas: fugir e esconder-se" (COUTO, 2009, p. 75). Assim, os derradeiros viventes eram desconhecedores de saudades e vazios de esperanças. Ausentes do mundo e privados de passado, os habitantes de Jesusalém ganharam novos nomes. "[...] Rebatizados nós tínhamos outro nascimento. E ficávamos mais isentos de passado" (COUTO, 2009, p. 37). Na cerimônia de desbatismo, Mateus Ventura se converteu em Silvestre Vitalício; Olindo Ventura, em Ntunzi; Orlando Macara passou a Tio Aproximado; e Ernestinho Sobra foi renomeado como Zacaria Kalash. Apenas Mwanito manteve o nome, pois, conforme lhe disse o pai, faltava-lhe um diabo. Mwanito havia nascido diversas vezes, sempre em Jesusálem, uma espécie de paraíso, criado à imagem e à semelhança do próprio Vitalício, à margem do caos da guerra e do caos da vida do ser humano.

Sofrendo de passado, que se tornara sua incurável doença, Silvestre Vitalício migrou da cidade dos homens para Jesusalém, "[...] a terra onde Jesus haveria de se descrucificar" (COUTO, 2009, p. 11) e ali instaurou um reino povoado por desmemórias e de solidão.

Ao fugir do mundo e se exilar em Jesusalém, Silvestre Vitalício se transformou em um monstro: "[...] A verdade é que no trono absoluto de sua solidão, meu pai se desencontrava com o juízo, fugido do mundo e dos outros, mas incapaz de escapar de si mesmo" (COUTO, 2009, p. 47); “[...] nosso pai tinha enlouquecido. E não era a benta e salvadora loucura. Era o demónio transzavado nele" (COUTO, 2009, p. 193). A transmutação do velho Vitalício em um ser monstruoso toma forma a partir do apagamento da identidade que o reconhecia na cidade do mundo e no mundo dos homens.

$\mathrm{O}$ afrouxamento dos laços da identificação da personagem com a cultura nacional "[...] uma das principais fontes de identidade cultural" (HALL, 2005, p. 47) - pode ser verificado pela maneira como Silvestre interdita em Jesusalém a evocação de antepassados. Em Moçambique os mortos não morrem nunca e os antepassados apresentam-se como deuses particulares de um clã, no entanto, "[...] Os Venturas não tinham antes nem depois" (COUTO, 2009, p. 110).

A busca por isentar-se de/do passado apresenta-se como evidência do esfacelamento da identidade de Silvestre, pois, segundo Stuart Hall,

[...] uma cultura nacional é um discurso - um modo de construir sentidos que influencia e organiza tanto nossas ações quanto a concepção que temos de nós mesmos [...] As culturas nacionais, ao produzir sentidos sobre 'a nação', sentidos com os quais podemos nos identificar, constroem identidades. Esses sentidos estão contidos nas histórias que são contadas sobre a nação, memórias que conectam seu presente com seu passado e imagens que dela são construídas. (2005, p. 50-51. Grifos do autor) 
Assim, a busca por esquecer-se do passado e desconectar-se de suas memórias promove o esfacelamento da identificação de Silvestre com a cultura nacional e, consequentemente, o esfacelamento de sua identidade cultural. A crise identitária da qual sofre a personagem constitui-se em uma infração, que é punida por meio de sua transformação em um ser monstruoso. Nesse sentido, o próprio Mia Couto afirma que:

[...] Uma das grandes questões que eu procuro em minha escrita é a procura de identidades. [...] que é uma coisa que nos move como pessoas, como famílias, como nações. É ao mesmo tempo uma coisa profundamente necessária. Precisamos ter uma identidade, não sei o porquê, mas precisamos ter uma identidade. Ficamos muito nervosos com a ausência dessa identidade. (RAHE, 2009)

O monstro que tomou corpo em Silvestre ameaça e põe em risco a vida dos habitantes de Jesusalém - os sobreviventes da morte do mundo. Ele proíbe, no território sob seu domínio, cantos, lágrimas ou rezas, aprisionando os últimos viventes a um reino de desmemória e de alheamento.

[...] Vou dizer uma coisa, nunca mais vou repetir: vocês não podem lembrar nem sonhar nada, meus filhos. [...] O que vocês sonham fui eu que criei nas vossas cabeças. [...] E o que vocês lembram sou eu que acendo nas vossas cabeças. [...] É por isso que vocês não podem nem sonhar nem lembrar. Porque eu próprio não sonho nem lembro. (COUTO, 2009, p. 17-18)

Ao privar não somente a si próprio, mas também aos demais habitantes de Jesusalém de passado e de futuro, a criatura monstruosa ameaça transformar também em monstros os últimos viventes, pois o monstro, materializando um castigo fundado em uma transgressão, contamina quem convive consigo. Ele adverte dos caminhos pelos quais não se deve seguir, chamando atenção para as fronteiras que não podem ser cruzadas, num jogo de intrincadas interdições.

O monstro

[...] impede a mobilidade (intelectual, geográfica ou sexual) delimitando os espaços sociais através dos quais os corpos privados podem se movimentar. Dar um pulo fora dessa geografia oficial significa arriscar sermos atacados por alguma monstruosa patrulha de fronteira ou $-\mathrm{o}$ que é pior - tornar-mo-nos, nós próprios, monstruosos. (COHEN, 2000, p. 41)

No reino de Silvestre Vitalício, como em todo território dominado pelo monstro, há quem ameace constantemente abandoná-lo - é o caso do Tio Aproximado, que mantém contato com a cidade do mundo, pois é o provedor de víveres para Jesusalém - porém não o faz. Há também aquele que questiona o monstro e seu poder não na tentativa de burlar sua vigilância e fugir de seus domínios, contudo na ânsia de compreendê-lo e compreender-se. Esse é Mwanito. 


\section{3 “Eu, Mwanito, o afinador de silêncios"}

A compreensão em Mwanito desenvolve-se com agudeza, pois a monstruosidade de Vitalício oferece-lhe maior risco, em razão de sua condição de duplo de Silvestre. A leitura de tal duplicidade manifesta-se em assertivas do narrador como estas: "[...] Conheci meu pai antes de mim mesmo. Sou, assim, um pouco ele." (COUTO, 2009, p. 29); “[...] eu nunca tinha exercido a minha própria infância, meu pai me envelhecera desde nascença" (COUTO, 2009, p. 123); e "[...] a sua vida [...] nunca me deixara viver. O estranho é que eu parecia estar morrendo na morte dele" (COUTO, 2009, p. 215).

O duplo revela-se como projeção consciente do conteúdo reprimido por Silvestre. Segundo Freud, na tentativa de lidar com o mundo externo e mediar questões internas, o ego reprime emoções, provocando uma ansiedade mórbida.

[...] se a teoria psicanalítica está certa ao sustentar que todo afeto pertence a um impulso emocional, qualquer que seja a sua espécie, transforma-se, se reprimido, em ansiedade, então, entre os exemplos de coisas assustadoras, deve haver uma categoria em que o elemento que amedronta pode mostrar-se ser algo reprimido que retorna. Essa categoria de coisas assustadoras constituiria então o estranho. (FREUD, 1996, p. 258)

O duplo refere-se ao estranho - algo estranhamente familiar, porém simultaneamente novo e desagradável - tanto quanto representa essa ansiedade, o "isso" reprimido que o indivíduo escolheu para esconder de si mesmo (cf. GUEDES, 2007, p. 27). Segundo Freud, o "[...] estranho não é nada novo ou alheio, porém algo que é familiar e há muito estabelecido na mente, e que somente se alienou desta através do processo da repressão" (1996, p. 258).

São os segredos guardados por Silvestre que geram o duplo Mwanito, "o afinador de silêncios”. Ele guarda tanto a dolorosa consciência do pai, por sua responsabilidade no destino de Dordalma, quanto a repressão da culpa em relação àquele destino. Dor, culpa e repressão dão origem ao filho/ao duplo.

O suicídio da mãe de Mwanito foi a maneira por ela encontrada de se revoltar contra a condição de propriedade que o casamento lhe imputou. Em uma dimensão maior, Dordalma rebela-se contra sua condição feminina em uma sociedade patriarcal.

Suicídio de mulher casada é o vexame maior para qualquer marido. Não era ele o legítimo proprietário da vida dela? Então, como admitir aquela humilhante desobediência? Dordalma não abdicara de viver: perdida a posse de sua própria vida, ela atirara na cara do teu pai o espetáculo de sua própria morte. (COUTO, 2009, p. 246)

E foi Mwanito quem, exercendo-se como o duplo de Silvestre e compreendendo-o, afastou o pai da lembrança eivada de culpa do suicídio da esposa, dando origem ao vislumbrar de um lugar onde o passado pudesse ser transformado em silêncio e o monstro ser exorcizado. 
“[...] Para Silvestre Vitalício, a minha vocação estava definida, tomar conta dessa insanável ausência, pastorear demónios que lhe abocanhavam o sono" (COUTO, 2009, p. 16).

\section{4 “Ordem de expulsão": considerações finais}

Para exorcizar o monstro Silvestre, e libertar si próprio e a humanidade de suas garras, Mwanito recebe ajuda. Caberá à visitante/enviada Marta a colaboração para a (re)invenção da identidade de Silvestre e de seu duplo. A presença da portuguesa na coutada desperta no menino saudades de sua mãe e estimula em Ntunzi, o irmão mais velho, o desejo carnal, intensificando nele a ânsia pelo porvir e em Mwanito o desejo pelo passado: "[...] Cada dia mais, eu a tinha como mãe. Cada vez mais, Ntunzi a sonhava como mulher" (COUTO, 2009, p. 152). A estadia de Marta em Jesusalém abala a autoridade do monstro.

[...] Uma única pessoa - ainda por cima uma mulher - desmoronava a inteira nação de Jesusalém. Em escassos momentos, tombava em estilhaços a laboriosa construção de Silvestre Vitalício. Afinal, havia, lá fora, um mundo vivo e um enviado desse mundo se instalara no coração do seu reino. (COUTO, 2009, p. 127-128)

É a chegada da visitante portuguesa que promove o reencontro dos homens residentes em Jesusalém com o passado. O passado, contudo, segundo Mia Couto,

[...] é quase sempre uma mentira. A parte do passado que não passa é uma construção, é uma releitura. Como os sonhos, nós nunca contamos os sonhos, porque sempre reelaboramos os sonhos quando contamos. O passado é composto por duas partes, aquilo que não passou, que é necessário lembrar, uma espécie de convenção quase silenciosa, às vezes manipulada, que impõe limites que depois fixam aquilo faz parte da história oficial; e outra parte do passado é esquecida, é enterrada. (RAHE, 2009)

Logo, a reatualização do passado, além de necessária, deve ser realizada por meio do exercício da memória, que constitui uma maneira de tradução dialógica do passado, que reconhece a "[...] comunicação com o 'outro' como formador do 'eu'. [...] O trabalho da memória parte do pressuposto de que o embate com o passado é guiado pela nossa situação presente" (SELIGMANN-SILVA, 2005, p. 212). O caráter dinâmico do passado, em constante transformação, é metaforizado quando Ntunzi lê para o irmão as cartas de baralho, destronadas pelo tempo, que resgatou em Jesusalém: “[...] Meu irmão fazia de conta que decifrava letrinhas entre barbas de reis e túnicas de damas. Eu sabia que ele inventava quase tudo, mas havia muito que ambos desconhecíamos a fronteira entre lembrança e mentira" (COUTO, 2009, p. 274).

Graças à presença de Marta, em consórcio com a compreensão de Mwanito, o exorcismo e a libertação do jugo do monstro fazem-se possíveis com o abandono de Jesusalém, o retorno à cidade do mundo e a consequente (re)familiarização com a cultura da 
terra e com o passado - que é sempre construído por meio da memória, da fantasia, da narrativa e do mito (cf. HALL, 1990). Com o regresso à cidade do mundo, o passado vem à tona, desencoberto por revelações que devolvem aos habitantes de Jesusalém a história da qual eles haviam sido privados e a possibilidade de um futuro livre do cerceamento das ameaças do monstro. A volta obriga Silvestre a um confronto com o passado do qual fugira e torna possível a (re)construção da identidade cultural do velho Vitalício e, consequentemente, do seu duplo, Mwanito.

Enfim, é dada a Ntunzi e a Mwanito a possibilidade de conhecer a história de seus familiares e da nação. A (re)atualização do tempo é feita por meio da memória, corporificada em uma narrativa que (re)põe o passado na vida das personagens. O relato da morte de Dordalma, a origem da bala alojada no ombro de Zacaria e a revelação de que Ntunzi não é filho de Silvestre, porém fruto da relação de Dordalma com o militar, compõem a (re)atualização da histórica de cada um dos ex-habitantes de Jesusalém.

O confronto com o passado, promovido graças à intervenção de Marta, permite que Silvestre se reconcilie consigo, por meio do perdão de seus filhos, Ntunzi e Mwanito.

A fronteira entre Jesusalém e a cidade nunca foi traçada pela distância. O medo e a culpa foram
a única fronteira. O medo me fez viver, recatado e pequeno. A culpa me fez fugir de mim,
desabitado de memórias. Era isso Jesusalém: não um lugar, mas a espera de um Deus que ainda
estivesse por nascer. Só esse Deus me aliviaria de um castigo que a mim mesmo havia
imposto. Contudo, só agora entendi: meus filhos, meus dois filhos, só eles me podem trazer
esse perdão. (COUTO, 2009, p. 276 )

O restabelecimento da harmonia entre o velho Vitalício e seu passado de culpa pode ser observado também na mudança de sua postura com relação às mulheres. Se, enquanto transmutado em monstro, acreditava serem elas todas putas, após o exorcismo Silvestre entregou à causa da associação de mulheres que lutava contra a violência doméstica o dinheiro deixado por sua esposa Dordalma.

Redescobrir o passado, entretanto, é apenas uma porção da tarefa de reinventar a identidade cultural. Tal empreitada não tem como objetivo reassumir aquilo que Robins chama de "tradição", ou seja, a recuperação de uma identidade anterior, pura, um retorno às raízes culturais. A redescoberta do passado tem como tarefa a (re)invenção de uma identidade cultural como produto de várias histórias e culturas interligadas, como resultado da negociação com novas culturas, sem que com isso os vínculos com as próprias origens e tradições sejam afrouxados, gravitando ao redor daquilo a que Robins denomina "tradução" (ROBINS, 1991 apud HALL, 2005, p. 87). 
[...] a cultura não é apenas uma viagem de redescoberta, uma viagem de retorno. Não é uma 'arqueologia'. A cultura é uma produção. Tem sua matéria-prima, seus recursos, seu 'trabalhoprodutivo'. Depende de um conhecimento da tradição enquanto 'o mesmo em mutação' e de um conjunto efetivo de genealogias. Mas o que esse 'desvio através de seus passados' faz é nos capacitar, através da cultura, a nos produzir a nós mesmos de novo, como novos tipos de sujeitos. Portanto, não é uma questão do que as tradições fazem de nós, mas daquilo que nós fazemos das nossas tradições. Paradoxalmente, nossas identidades culturais, em qualquer forma acabada, estão à nossa frente. Estamos sempre em processo de formação cultural. A cultura não é uma questão de ontologia, de ser, mas de se tornar. (HALL, 2008, p. 43)

Na empresa de (re)invenção da identidade, o conhecimento do passado histórico e o resgate da tradição devem ser utilizados na construção da identidade cultural, sem que com isso se conduza a um fundamentalismo cultural que procura a auto-afirmação do Eu-Nação via extermínio do outro (cf. SELIGMANN-SILVA, 2005, p. 205). O próprio Mia Couto reitera a proposição de Seligmann-Silva:

[...] A ideia que eu combato muito é que há agora uma grande tendência, digamos, tradicionalista em dizer que a nossa verdadeira identidade tem que ser procurada no passado. $\mathrm{E}$ isso não constrói nada. A nossa verdadeira identidade tem que ser feita por costuras. Tem que se buscar ao passado aquilo que já sabemos que é uma operação que vai escolher, que vai selecionar aquilo que tem que ser resgatado com memória. Mas tem que se costurar isso com alguma coisa. E que coisa é essa? E aí é difícil, porque, de fato, o mundo de hoje é um mundo que oferece coisas muito fragmentadas, muito dispersas. Que modernidade vamos escolher? A resposta tem que ser 'nós vamos escolher aquela que nós fizermos', não podemos escolher, não é uma coisa que se vá ao mercado, ao shopping e vou comprar um pacote de modernidade. (RAHE, 2009)

Logo, é preciso, para a construção identitária fomentadora do exorcismo do monstro, o casamento entre tradição e modernidade. A resposta, segundo Hall, "[...] não é apegar-se a modelos fechados, unitários e homogêneos de 'pertencimento cultural', mas abarcar os processos mais amplos - o jogo da semelhança e diferença - que estão transformando a cultura no mundo inteiro" (2008, p. 45).

Assim, Silvestre Vitalício e seu filho Mwanito, embora se libertem da condição monstruosa, tem no aprisionamento ao passado de que ambos são vítimas uma patologia. Esse estado patológico aponta para a construção de uma identidade fundada exclusivamente por meio do resgate da tradição.

Para se livrar da doença - constituída de "um encaroçamento do passado, uma maleita feita de tempo" (COUTO, 2009, p. 256) que, como duplo, herdara do pai - Mwanito escreve: "Eu herdara a loucura de meu pai. Por longos períodos era atacado por uma cegueira selectiva. $\mathrm{O}$ deserto se transferia para dentro de mim, convertendo a vizinhança num povoado de ausências. [...] Deixo de ser cego apenas quando escrevo" (COUTO, 2009, p. 275). 
A escrita, representação metafórica da modernidade que deve costurar-se à tradição, ensinou a Mwanito que "as palavras podem ser o arco que liga a Morte e a Vida" (COUTO, 2009, p. 241).

Um pequeno graveto rabiscava na areia do quintal e eu, deslumbrado, sentia que o mundo renascia como a savana depois da chuva. [...] A escrita era uma ponte entre os tempos passados e futuros, tempos que, em mim, nunca chegaram a existir. [...] A escrita me devolvia o rosto perdido de minha mãe (COUTO, 2009, p. 41-42).

Mwanito reconstroi Jesusalém e os tempos de sua infância por meio da escrita e continua por buscar o rosto de Dordalma nos tempos vindouros: “[...] meu pai estava errado: o mundo não morreu. Afinal, o mundo não chegou a nascer. Quem sabe eu aprenda, no afinado silêncio dos braços de Noci, a encontrar minha mãe caminhando por um infinito descampado antes de chegar à última árvore" (COUTO, 2009, p. 277). É preciso, portanto, que Mwanito não se esqueça de que nunca mais haverá Jesusalém, bem como não existirá a cidade préJesusalém, pois se o monstro, numa primeira visada, impõe diferenças, por outro lado, ele é uma tentativa de composição do outro e, consequentemente, de composição de nós mesmos. Ao assombrar as fronteiras daquilo que pode ser ter sido pensado, dito e feito em um tempo pretérito, o monstro, no caso de Antes de nascer o mundo, é um artifício para (re)dimensionar os parâmetros em torno dos quais a identidade daqueles que se situam do lado de dentro das fronteiras pode ser (re)construída.

\section{Referências}

BELLEI, Sérgio Luiz Prado. Monstros, índios e canibais. Ensaios de crítica literária e cultural. Florianópolis: Insular, 2000.

COHEN, Jeffrey Jerome. A cultura dos monstros: sete teses. In: COHEN, Jeffrey Jerome (Org.). Pedagogia dos monstros. Os prazeres e os perigos da confusão de fronteiras. Trad. Tomaz Tadeu da Silva. Belo Horizonte: Autêntica, 2000. p. 25-60.

COUTO, Mia. Antes de nascer o mundo. São Paulo: Companhia das Letras, 2009.

FREUD, Sigmund. O Estranho. In: Obras psicológicas completas de Sigmund Freud: edição standard brasileira. Trad. Jayme Salomão. Rio de Janeiro: Imago, 1996.

GUEDES, Rodrigo Silva. Secular readings of goog and evil in R. L. Stevenson's Strange Case of Dr. Jekyll and Mr. Hyde. Belo Horizonte, 2007. Dissertação (Mestrado em Letras - Estudos Literários) - Faculdade de Letras, Universidade Federal de Minas Gerais.

HALL, Stuart. Cultural Identity and Diaspora. In: RUTHERFORD, Jonathan (ed.). Identity: community, culture, difference. London: Lawrence \& Wishart, 1990. p. 222-237. 
A identidade cultural na pós-modernidade. Trad. Tomaz Tadeu da Silva. Rio de Janeiro: DP\&A, 2005.

Da Diáspora: identidades e mediações culturais. Trad. Adelaine La Guardia Resende, Ana Carolina Escosteguy, Cláudia Álvares, Francisco Rüdiger e Sayonara Amaral. Belo Horizonte: Editora UFMG, 2008.

JEHA, Julio. Monstros como metáforas do mal. In: JEHA, Julio (Org.). Monstros e monstruosidades na literatura. Belo Horizonte: Editora UFMG, 2007. p. 9-31.

As origens do mal. In: JEHA, Julio; NASCIMENTO, Lyslei (Orgs.). Da fabricação de monstros. Belo Horizonte: Editora UFMG, 2009. p. 11-23.

RAHE, Juliana Ciambra. Entrevista inédita com Mia Couto. São Paulo, SESC, 27 jun. 2009.

SELIGMANN-SILVA, Márcio. Globalização, tradução e memória. In: O local da diferença: ensaios sobre memória, arte, literatura e tradução. São Paulo: Ed. 34, 2005. p. 205-213. 